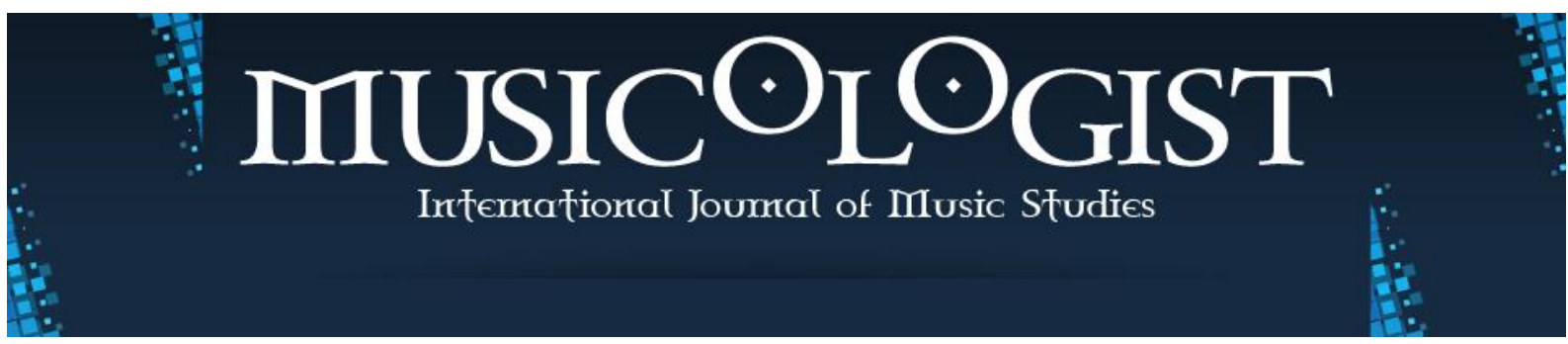

Trabzon University State Conservatory @ C 2017-2021

Volume 5 Issue $2 \quad$ December 2021

Research Article

Musicologist 2021.5 (2): 133-165

DOI: $10.33906 /$ musicologist.906765

\author{
NANA MZHAVANADZE \\ Universität Potsdam, Germany \\ mzhavanadze@uni-potsdam.de \\ orcid.org/0000-0001-5726-1656
}

FRANK SCHERBAUM

Universität Potsdam, Germany

fs@geo.uni-potsdam.de

orcid.org/0000-0002-5050-7331

\title{
Svan Funeral Dirges (Zär): Cultural Context
}

\begin{abstract}
This article is a companion paper to Scherbaum and Mzhavanadze (2020), Mzhavanadze and Scherbaum (2020) and Scherbaum and Mzhavanadze (2021). Together they describe the results of an interdisciplinary study of the three-part funeral dirge of Svan zär ('zari' in Georgian). In the present paper, we provide all the contextual (ethnographic, ethnological, historical) data that we collected from various written and/or oral sources and then processed and organized in a comprehensible way to help the reader better understand this unique phenomenon. We believe that in order to help answer the basic question of 'how zärs work,' the results of the acoustical, musicological, and phonetic (as well as language-music interface) analyses in the other three articles must be interpreted through an understanding of the full context of this unique cultural behavior.

Thus, not only did we collect and integrate all the related data and review the literature, but we also raise and discuss some problematic issues, such as, for example, the etymology of the term zär. We also offer an interpretation/description of some conflicting historical data to generate interest for its further research. In addition, we introduce the reader to some details of our field research $(2015,2016)$, as they may be of great importance when discussing or interpreting the results of the analyses presented in other (analytical) parts of this interdisciplinary study.
\end{abstract}

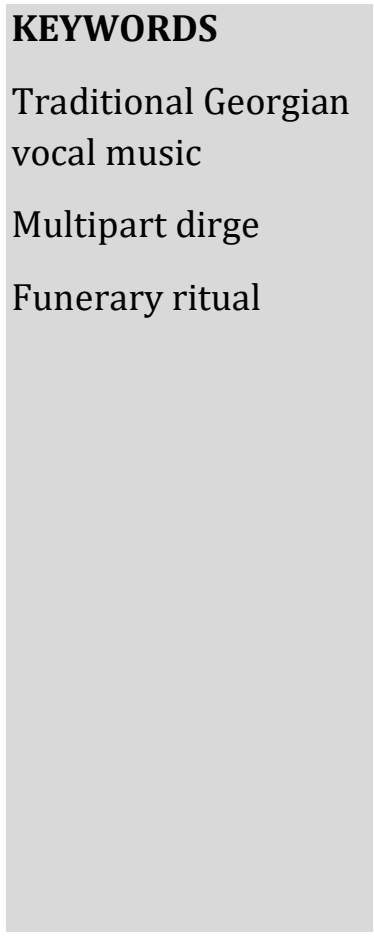




\section{Preface}

The scene takes place in the village of Lat'li (in Georgian Lat'ali, see Figure 1), in Upper Svaneti. It is the funeral of Pridon, the venerable and revered village doctor who had faithfully served his community over decades. Flanked by a group of villagers, Sima Chamgeliān, an elderly village woman approaches the body of Pridon, laid out in the center of the room, to pay him her last respects and weep over the deceased. Quietly at first, but gradually growing more dramatic and louder in its intensity, her voice manifests intense vocalizations, with increased weeping and sobbing. Each phrase of her agonized litany ends with a refrain exclamation 'way Pridon!' (woy Pridon!), which is followed, in turn, by the other women mourners with loud utterance-type sobbing. Now, in a recitation, Sima praises the good deeds and grace of the deceased, beseeching Pridon to take good care, in the afterlife, of her relatives and other villagers who have also passed away, and requests him to let his fellow deceased know how difficult life has become, here, on the Earth without their presence.

Directly after her tribute ends, a procession of men enters the room, led by an elder male. In similar form, the old man also weeps over the corpse, lamenting the sorrow and loss of the villagers, using powerful vocabulary and emotions. From time to time he strikes his forehead evoking a response from the attendees of varied utterances and sobbing.

Meanwhile, under a tree in the yard, a small table is laid out with plates of food, and carafes of wine and "Haraq"” (a local vodka made from fruit). Some men sit behind the table on wooden benches. From time to time, at certain intervals, they rise to their feet, remove their hats and begin to chant a three part 'song' without discernible linguistic form, called zär. The sound of the zär is challenging to describe in musical terms. The men vocalize specific vowels and utterances in a very slow tempo, moving mainly stepwise up and down from one pitch to another, articulating with very powerful, loud and dirge-like, tensed voices. Short phrases dominate, consisting of vowels only, and are interspersed with utterance interjections such as 'woy' or 'wuy'. Gradually the sound of the chant intensifies, with increased tension and volume.

There appears to be no discernible link between the performance of the zär and the solo and responsorial keening emanating from inside the house. Sometimes only mourners inside the house wail, while zär chanters outside rest a while, and vice versa. Every now 
and then, utterances from inside can be heard over and above the sounds of the zär simultaneously chanted outside.

Shortly afterwards, another procession of villagers approaches the gate, with several men chanting zär. These are the men from the neighboring village of Lenjār, who have come to pay their respects, singing their own village variant. This musical offering ends as they approach the door of the house and enter en masse to pay farewell tributes to the deceased and express condolences to the family. Soon the group reemerges and joins the ranks of the assembled chanters. This pattern then repeats for a third time, when another group of men from the villages of Lower Bal (the lower region of Upper Svaneti) arrive to contribute their own variant of zär. At intervals throughout the morning the three assembled chanting groups chant zär from their own communities, until it is time for the body of the deceased to leave house in a slow procession, to begin the journey to its eternal home. Although all versions of zär are believed to be different, to our untutored ears, they sound remarkably similar. Now, in the early afternoon, as the body is slowly escorted to its final resting place in the cemetery, the assembled procession sings "Ts'mindao Ghmerto," the Trisagion hymn, in Georgian. Upon arrival at the final resting place at the grave site, zär is chanted for one last rendition before the body is finally laid to rest.

\section{Introduction}

The above-described funeral was attended and documented by Madge Bray and one of the authors (N. M.) in the village of Lat'li1 ${ }^{1}$ (Figure 1) in the Summer of 2010. It portrays almost all types of ritualized keening witnessed and reported in different parts of Georgia. It demonstrates two distinct forms of keening: firstly, a solo and responsorial model (a solo mourner both female and male responded to by sobbing utterances from a group of fellow mourners) (Giorgadze, 1987: 45; Chelidze, 1987: 163-166, Azikuri, 1986, 2002; Sikharulidze, 1970: 59-60), which is based on human emotion and fully improvised. Secondly, another distinct form emerges, where a group of males chant in well-organized

\footnotetext{
1 To ensure that the transcription of Svan texts (including proper names) is close to the original and reflects the phonetic peculiarities of Svan language, we have combined two transcription systems: for consonants - romanization of Georgian via using Latin script (national system, 2002; https://en.wikipedia.org/wiki/Romanization_of_Georgian); for vowels and some Svan-specific consonants - $\quad$ TITUS http://titus.fkidg1.uni-frankfurt.de/didact/caucasus/kaukvok.htm\#SvanUBal and http://titus.uni-frankfurt.de/didact/caucasus/ kartlaut.htm
} 
and coordinated musical form, without verbal text, but rather constituting of peripheral vocabulary, such as wai, woi, wui, etc. (Lamberti, 1938: 62; Milaneli, 1964: 90; Tsuladze, 1971; Bolle-Zemp, 1997).

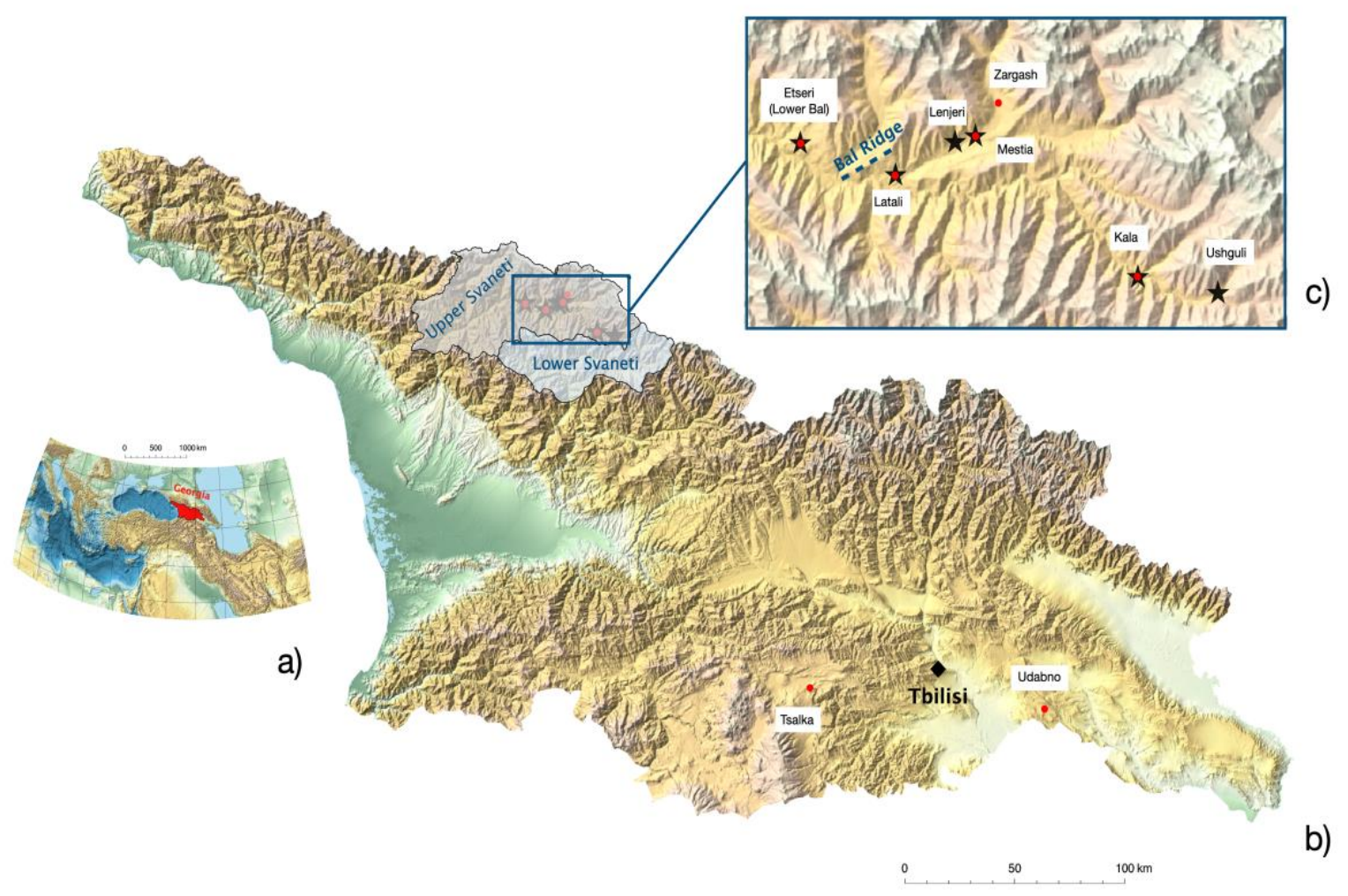

Figure 1. Geographical situation. a) The location of Georgia in its regional context. b) Study area and recording sites (marked by red solid circles) of the field expedition of 2016. c) Locations of recording sites (red solid circles) and locations of origin of $z \ddot{a r}$ (black stars) within Upper Svaneti. The Bal ridge (altitude-wise) divides the Lower Bal and Upper Bal regions of Upper Svaneti.

The ritualized keening ${ }^{2}$ in its wide variety of manifestations (solo, choral, etc.) is a universal phenomenon attested all over the world, which can be heard in culturally and geographically distinct areas in different parts of the world. Examples of it include fuatanga in the Tikopia island (Love and Kaeppler, 2017: 853-855; Firth and McLean, 2006), dawawa in Central America (Graham, 1984), iavsema in Mordovia, Russia (Jordania, 2006: 663), and Albanian vajtim (Kondi, 2012). In Svaneti (as well as in other parts of Georgia), in addition to the local equivalents of the funeral forms described

\footnotetext{
${ }^{2}$ To avoid confusion in the use of disputable terms such as: keening, lamenting, wailing, crying, etc. applied to describe ritualized mourning soundscape, in the article we will employ the term "keening "for all types of mourning sound manifestations based on improvisational expression of sorrow over loss (solo, responsorial, etc.) and dirge for organized polyphonic chant such as zär. This will create a clear delineation between two distinctive and radically different ritual mourning styles sharing the same functional locus.
} 
above, there is a musically organized funeral hymn, aka zär, the musical equivalent of which does not seem to be found anywhere else.

This present study focuses on an analysis of Svan zär from Upper Svaneti ${ }^{3}$ which, together with a few examples with a similar name bsøo (zari, in Georgian dialects) and function from other parts of Georgia, represents a unique musical mourning behavior. The large majority of the material, which is the subject of the analysis in the present study, has been collected (often in its natural context) by us during a three-month field expedition in 2016 to Upper Svaneti and to Svan eco-villages near Tbilisi, the capital of Georgia. The study focuses on two major aspects of zär, which, in our opinion, cannot be separated from each other. In this paper we will discuss the socio-cultural, historical, and ethnological context of the chant. On the other hand, in papers Scherbaum and Mzhavanadze (2020) and Mzhavanadze and Scherbaum (2020) we quantitatively analyze the musicological properties of zär, using computational analysis of acoustical features (such as the tuning systems and scales) and musical vocabulary (chord progressions, melodies, rhythm, etc.). By combining these perspectives, we aim to obtain a more holistic view of $z a ̈ r$, its musical language and its sacred function within the funeral rites of the Svan people.

In order to better interpret the results of musicological and computational analysis (Scherbaum and Mzhavanadze (2020) and Mzhavanadze and Scherbaum (2020)) and to better understand the phenomenon (to answer the question "how does zär work?"), we extended our approach to consider broader contextual issues. In particular, we used the so-called "tselostnïy analiz" (L. Mazel, W. Zuckerman's method of holistic analysis), as well as the ethnographic practice known as "thick description" (promoted by anthropologist C. Geertz, 1973). ${ }^{4}$ The results of the interdisciplinary contextual study revealed the complex nature of the problem and showed how difficult it is to provide a single definition of zär, given the heterogeneity of ethnographic, sociological, and musicological data (from both historical and contemporary practice) and the etymological confusion. However, we have ventured to offer a few interpretations and

\footnotetext{
${ }^{3}$ We did not work in Lower Svaneti, so the research mainly focuses on the repertoire of Upper Svaneti. Therefore, the results of the analysis and conclusions cannot be generalised to include the music of Lower Svaneti, which shows signs of a stronger influence of neighbouring musical dialects. ${ }^{4}$ The concept originated earlier with Gilbert Ryle but was popularised by Geertz.
} 
point to some important questions, further exploration of which may shed light on some questions that have not yet been answered.

\section{Svaneti and Svans 5}

Svaneti is one of the highest mountainous regions in Georgia (Figure 1). Surrounded by 3000 - 5000-meter peaks, it is located in the northern part of Western Georgia on the southern slopes of the Caucasus Range. Svans also inhabit the K'odori gorge (or Svaneti of $D a ̈ l)^{6}$ in the Gulripshi district, in Apkhazia.

Svaneti is divided into Upper (free) Svaneti (Enguri Gorge) and Lower (Tskhenists'qali Gorge) Svaneti. ${ }^{7}$ The administrative center of Upper Svaneti is Mest'ia, whereas Lent'ekhi is the central town of Lower Svaneti. Upper (free) Svaneti itself is subdivided into two (Upper and Lower Bal) regions by the Bal mountain range (Figure 1).

Communities of 'free Svans' traditionally occupied the eastern part of Upper Svaneti, the so-called Upper Bal district. Unlike other parts (including the communities of Lower Bal, which were the dominion of the Prince Dadeshkeliani) of early Svaneti, Free Svaneti was not subject to princely dynasties and was devoid of typical feudalism, with no family occupying a prominent position. It consisted of self-governing communities with a tribal system of law. Thus, 'free Svaneti' was not subordinated to a centralized government until their struggle for independence was finally suppressed by Russian raids, first in the mid19th century, and then in 1921, when they were conquered by Soviet Russia.

Sources from Antiquity refer to Svans as 'Misimyans,' which is a Greek variation of the Svans' name for themselves $\partial \partial^{2} \hat{y} s 5$ 'mashwan' (Topchishvili, 2010: 129). The Svans originally settled in a larger area and inhabited a significant part of Lechkhumi and Rach'a. They also lived in one area of present-day Samegrelo and on the territory of present-day Abkhazia, as evidenced by the numerous Svan toponyms found in this part of Georgia. Svan toponyms, as well as Svan-style towers, are also confirmed in the North Caucasus, in the upper reaches of the Tergi, Bakhsan, and Kuban rivers (Lavrov, 1950).

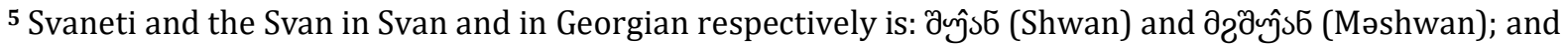

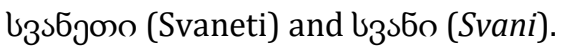

${ }^{6}$ In Svan mythology (in the pantheon of Gods) Däl, the goddess of high mountains and rocky terrain animals is one of the highly respected deities.

${ }^{7}$ In Upper Bal dialect: bällunchu (lower Bal) and bällunzhu (Upper Bal). In Georgian respectively balskvemo and balszemo.
} 
Svaneti obeyed first the kings of Colchis, then its successors Lazika (Egrisi) (until the 9th century), then the Kingdom of Abkhazia (of Western Georgia), which from the 11 th to the 15 th century was part of the united Georgian kingdom. Later, Georgia politically split into three states and five semi-independent provinces, including Svaneti.

Svans have always remained a cultural sub-group of the Georgian nation, and they have contributed greatly to the creation of what is now known as Georgian culture. The language of Svans is one of the four Kartvelian languages (the others being Georgian, Megrelian, and Laz). As Svan is a spoken language only, all historical documents in Svaneti are written in Georgian. ${ }^{8}$

In the past, the social organization of Svans was tribal. They lived in large families of different generations. These families were united in small villages and larger communities. They were governed by a centuries-old community legal system, orally passed down from generation to generation and represented by an elected council headed by an elected leader dsbü̃ono (makhwshi), usually a respected elderly man. Stock raising as well as hunting remained the main agricultural activities of the Svans. Most of the day to day activities in the communities to date were carried out cooperatively. Most of these activities were closely related to the Svans' strong religious beliefs (Eristov, 1898; Dadwani, 1973; Gasviani, 1991; Nizharadze, 1962, 1964).

In a sense, Svaneti can be considered a living museum, as various customs and rituals are still actively performed here. Some rituals are considered archaic and pagan (even preChristian) (Bardavelidze, 1941; Javakhishvili, 1928; Rosebashvili, 1982: 45-46). Although Christianity was preached by the first disciples in this region in the first century (Kaukhchishvili, 1955: 42-43), it is unknown when Svans formally adopted the new religion. Most of the churches ${ }^{9}$ preserved here (Upper Svaneti) date back to the $10-15$ th centuries. Together with traditional Svan medieval towers, ${ }^{10}$ they create an outstanding architectural 'image' of Svaneti. During historical hardships these churches became sanctuaries of material Christian treasures (icons, scriptures, crosses, etc.), as these

\footnotetext{
8 Besides, more likely, Svans have incorporated and processed some traits of the neighboring regions in the northern part of the Caucasus via on and off relationships with them which continue to present day.

${ }^{9}$ About 100 churches and 200 towers have been preserved in Svaneti up today.

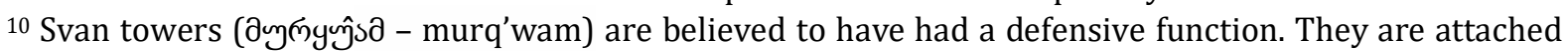
by a lower extension which used to be a living space for Svans' big families as well as for livestock.
} 
objects were brought to Svaneti from other monasteries and churches in Georgia for safekeeping. In addition, Svans had begun to develop their own original Christian iconography as early as the 9th-10th centuries (Kenia, 2010: 6). It should be noted that only Svaneti maintains the tradition of frescoes on the outer walls of churches, and that sometimes, these frescoes depict non-Christian themes (for example, 'AmiranDarejaniani' by Moses Khoneli). Such non-canonical fragments, preserved in Christian churches, reveal the free nature of Svans and their unique understanding of Christianity.

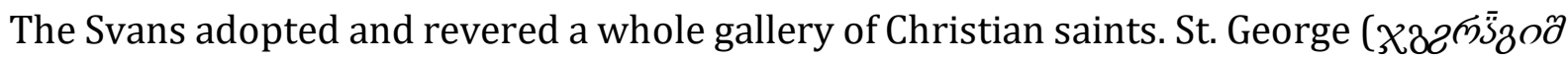

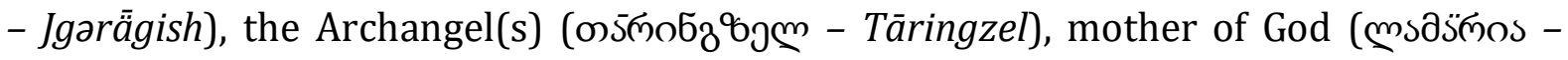

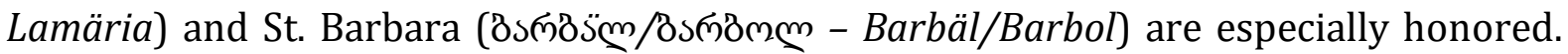
Nevertheless, their perception of the Christian pantheon is somewhat pagan (Javakhishvili, 1928; Bardavelidze, 1939, 1941; Chartolani, 1977: 6-16). Svans ascribe these saints to possess higher power and rank them analogously to the great God bmas

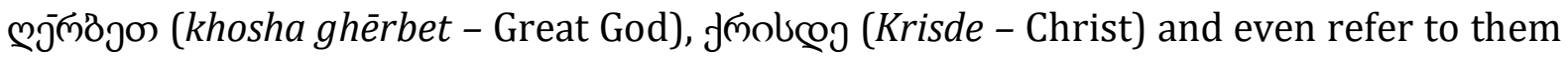
as Gods. On the one hand, Svans revered Christian attributes so dearly that anyone who stole anything from a church used to be sentenced to death (Silogava, 1988: 194). On the other hand, however, they seem to not always have had the same respect for priests and canonical Orthodox services (Uvarova, 1904: 282; Gabliani, 1927: 25; Chimakadze, 1913). ${ }^{11}$

The Svans' extremely religious worldview, cosmogony, and ethical and cultural values are reflected in all levels of their lives. V. Bardavelidze, who studied the Svans' ritual lives, states that at some point, calendar festivals in Upper Svaneti reached 160 per year (Bardavelidze, 1939). Many of these rituals are still celebrated today. Most of the calendar rituals are performed by the community members themselves. The majority of them represent folk forms of Christian festivals and are performed at churches which architecturally serve a double function. One part of the building is the church itself where the para-liturgy is performed. The other part attached to it (msco̊s $\tilde{\text { d }}$ ladbash), features

\footnotetext{
${ }^{11}$ According to some accounts, Svans did not allow women to go to church and if they should do they would be liable to be stoned. Men would be permitted to go to church twice a year - on Easter day and on Christmas day. Priests themselves had no control over the church and the key would be kept by someone else who was chosen by the community to guard the church (Phillips-Wolley, 1883:84-86; Kovalevskiy, 1930:115, 116).
} 
in the preparation of the sacred meal (including the blood sacrifice). Music of predominantly folk origin plays a central role in such celebrations. Most of the repertoire consists of prayers, round-dance hymns and ballads of different content, also featuring Svans pagan beliefs (for example the cult of the goddess of hunting and protector of mountain animals). The festive repertoire contains only two church prayers in Georgian (but in Svan style) which have been adopted from the Orthodox service. ${ }^{12}$

Even though Svan music is an integral part of what is known as Georgian traditional music, Svan singing repertoire can be distinguished from other Georgian musical dialects by its special musical qualities. The Svans' peculiar religiosity is manifested mainly in ritualized festivals and customs expressed in a specific musical language, which is believed to reflect some archaic qualities. Thus, ethnomusicologists have suggested that the Svan soundscape (alongside with that of the Khevsurs, in the eastern part of the country) has preserved the oldest layers of Georgians' traditional music making (Arakishvili, 1950; Chkhikvadze, 1948: 29; Aslanishvili, 1954: 87), a view which is shared by ethnomusicologists of the new generation as well (Jordania, 2010: 236-239; 2012, Gabisonia, 2012; Baiashvili, 2012).

Music is also an attribute of non-calendar ceremonies and rites such as weddings, funerals, and a wide range of death-related (memorial) rituals, which also represent collective, community activities, often strictly regulated and structured. Among these mourning rituals, there are only a few, in which the role of music is particularly remarkable. In this respect, the funeral rite of the Svans deserves special attention. As already noted in the introduction, it features a special polyphonic funeral chant, the analogues of which can be found only in very few parts of Georgia. Only in Svaneti, however, has this unique form of mourning ritual dirge survived until the present day.

\section{Funeral rites of Svaneti}

\section{Funeral rite terminology}

As in all cultures and geographical areas, the phenomenon of death and its mysteries has been one of the greatest subjects of concern for the Svans. Therefore, funeral and

12"Oh, Holy God!" (there are two variants of this chant, one of which is a funeral chant) and "Oh, God, have mercy on us!" 
memorial rites have been among the most powerful and resistant forms of Svan cultural self-expression. According to their cultural view of death, it is a transition to another world where souls continue their 'being' and have the same needs as the living. Therefore, Svans do their best to comfort the deceased souls and 'provide' them with all their needs: food, clothing, music, etc. so that they can survive well in the afterlife. ${ }^{13}$ At the same time, the deceased souls are believed to gain superpowers, which enable them to influence the lives of the living. Therefore, much depends on the behavior of the living and much stock is placed on individual human generosity in offering comfort to the dead in order for their future mercy and compassion to be bestowed on those who remain on the earth.

This explains the abundance of death-related rituals in Svaneti, including both burial and memorial services. The memorial rites are especially diverse and involve a wide

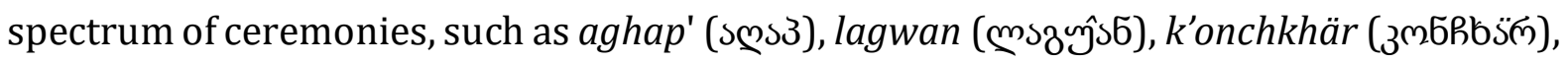

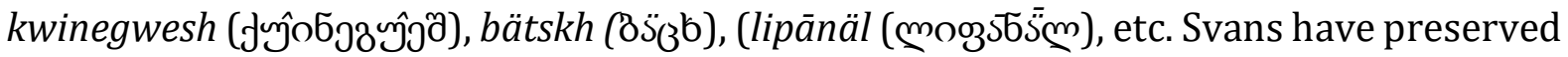
a special ritual called kwuini lit'khe (fyônobo mośbj) meaning 'bringing the soul back,' which is applied when a person dies away from home, up to the present day. ${ }^{14}$ Music plays a special role in some of these rituals (e.g. bätskh, ${ }^{15}$ lipānäl,16 and kwuini lit'khe).

The terminology for mourning vocal expressions in Svaneti marks different forms and involves:

\footnotetext{
13 This faith was so strong that some Svans prepared a memorial meal for themselves long before their death, believing that after death, they would have everything ready in heaven (Dadwani, 1973:12-14).

14 "According to Svanetian belief, if a person was to die outside his/her house, a soul departed from the body would not find a way back home and would be lost forever. That is why, when the mourning family was returning the body of the deceased, it would also take care of bringing the soul back home. Grievers participating in the ritual (kwuini lit'khe) would bring a rooster and the chäng (a lyre) and visit the place a person was found dead. There they would play on the chang, mourn and beg the soul to return. If a rooster crowed on the way back to the house and the strings of chang ( $\mathrm{Bs}_{3}$ ) also played smoothly, it was proof that the soul had been found and was following the relatives back home." (Chamgeliani and Khizanishvili, 2019). 15 This memorial ceremony was not mandatory for everyone and mostly was executed by well off families. They invited the neighbourhood and hosted them in order to ease the deceased's souls. Unlike ligwän when music is not allowed, bätskh is rich in singing and dancing (Eristov, 1898:45). The musical repertoire of such services is not particularly related to the ritual but is optional and can involve the songs and dances performed at other occasions as well.

${ }^{16}$ lipānäl - the New Year cycle celebration dedicated to the souls of the dead. The festival starts one day before Epiphany (adgom), on January 5th (old style) each year and lasts for 3-4 days or a week. On this day, the ancestral souls are invited to visit their living relatives and stay for a couple of days. Each family carefully prepares for this ritual. A special table is laid out for the souls, family members tell fairy tales, sing and play on the ch'uniri (a traditional bowed string instrument) for the dead visitors, normally the family members and relatives. Lipānäl lasts until the following Monday. On Monday morning, the souls of the dead are sent off with blessing (Chamgeliani and Khizanishvili, 2019).
} 


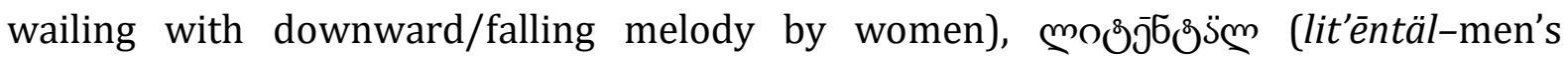

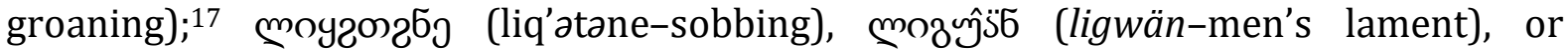

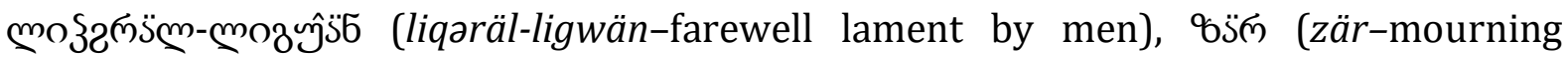
chant/dirge by a group of men).

While most of the above-mentioned mourning forms have been acknowledged to exist in various corners of the world, the zär - a male polyphonic funeral hymn - stands out as a special attribute of the Svans' mourning ritual (also present in some other parts of Georgia) for its remarkable role within the funeral context and for its peculiar musical qualities. Therefore, below we scrutinize this phenomenon in depth. This seems to be especially important because the unique tradition of zär, which has survived up today only in Svaneti, is in danger of extinction given that old masters of the chant are passing away one by one, and the new generation does not seem to be eager to continue the tradition. This is, obviously, one of the reasons that over time, only few zär out of many have survived in Svaneti.

\section{The role of zär in the Georgian funeral tradition}

\section{Etymology}

The term zär is not unique to the Svan funeral repertoire. The Georgian equivalent of it is zari ( $\mathrm{bs}$ (n)) denoting several mourning forms. However, in the context of the funeral rite, the description of zari is very diverse and heterogeneous, which makes it complicated to trace it back to its origins and reconstruct its development. The investigation of earlier references to the term zari reveals a spectrum of its connotations, such as, for example: a bell, horrific fear (Orbeliani, 1949; Kotetishvili, 1961: 234, 251, 273); loud noise, or an instrument (Rustaveli, 2017: 313, 334). In later references, it gains a mourning connotation, signifying a form of lamentation over a deceased (Kekelidze, 1956: 224, 228; Kazbegi, 1974: 158-159; Sikharulidze 1970: 399-400; Javakhishvili, 1938: 280).

In Western Georgian ethnographical writings zari is also mentioned in the funeral context, however, the accounts are somewhat confusing. A. Lamberti, an Italian missioner

\footnotetext{
17 S. Bolle-Zemp who travelled throughout upper Svaneti and witnessed a funeral rite, describes lit'ēntäl/li'tenturäl and accounts that "several men come up close to the body and make their lamentations (lit'enturäl) where they ritually cry for the dead one, moving their hands from the forehead to their knees, a number of times." (Bolle-Zemp, 1994). This type of keening by men seems to be rare now.
} 
who travelled in Georgia in the XVII c. describes zari as something like singing and crying at the same time, based on utterances instead of words (Lamberti, 1938: 62). 18 A. Tsuladze recounts the zari tradition in Guria as a "mourning march-wailing and music of mourning ... a wordless chanting," which needs only three people (Tsuladze, 1971: 156157). D. Arakishvili refers to zär as a 'mourning song' (Arakishvili, 1954: 5).

Zari, in association with group behavior is defined only in a dictionary of old Georgian language and means "people, (smooth, harmonious) team" (Abuladze, 1972: 162). It is also described as a group form of mourning by D. Machabeli (in Giorgadze, 1987: 45). ${ }^{19}$

The generalization of the accounts of zari all over Georgia allows to outline two major forms of the lament: a) it involves a leading mourner wailing over the deceased and accompanied by a group of $\partial \jmath$ bs b) a group dirge. 20

The varied references to the origins of the context and performance form of $z a ̈ r$ in Svaneti are not clear or consistent either. Today, zär is strictly labeled as a mourning ceremonial dirge, which is sung without a verbal text, and which is based on utterances and exclamation syllables and vowels. Moreover, it is heard through the whole funeral ceremony until the moment when the body is buried, and people leave the graveyard. However, earlier accounts about its function and role in the mourning ritual, as well as its verbal content, vary. According to Z. Paliashvili, zär is a 'mourning ritual song' performed by group of men as the coffin of the dead body is carried to the cemetery. He also notes that via zär chanters praise the deeds of the deceased and give some characteristics of his/her personality (Paliashvili, 1909). ${ }^{21}$ Very similar is the description of the funeral procession made by C. Phillips-Wolley, a British ethnographer who had

\footnotetext{
18 cf. "song-like keening" by A. Seeger (1981:172).

${ }^{19}$ It is noteworthy to point out here that in Iranian Persian زار (zâr) means a groan, lament. It has the same significance in the Urdu language as well.

${ }^{20} \mathrm{~N}$. Chokhonelidze notes that the mourning connotation of zari emerges in writings from the medieval and modern literature, and quotes an excerpt from the Georgian translation of the famous "Shahnameh" by Ferdowsi (Chokhonelidze, 2016:80). It could well be that as the popularity of "Shahnameh" grew in Georgia, the mourning implication of zari was adopted and integrated into the Georgian language. This could explain why it is missed in The Georgian Dictionary by Sulkhan-Saba Orbeliani (18th century) (N.M.).

${ }^{21}$ Z. Paliashvili's reports on the form and context of the performance of zär as follows: "The singers line up in rows, put their clubs (spearlike, and carried by every Svan) over their shoulders, form a funeral procession and sing this hymn, which - in musical content - is both majestic and terrifying and the procession is fine to view" (Paliashvili, 1909:8-9). This seems to have been copied by other authors later (I. Javakhishvili, D. Arakishvili, A. Dirr).
} 
attended a funeral in Svaneti himself. He writes: "Forming a procession of from twenty to thirty, his companions follow their dead fellow, carrying their alpenstocks over their left shoulders, and keeping up a chorus of “wai! wai!"22 as they march" (Phillips-Wolley, 1883: $95,96)$.

However, some authors claim zär to have been performed at the funeral only in special cases when a very old person died (Akhobadze, 1957: 21; Arakishvili, 1950: 23; PhillipsWilley, 1883: 95, 96). ${ }^{23}$ Today zär is sung for any deceased. Moreover, some early authors, portraying funeral ceremonies including the last procession to the cemetery, never mention zär, but describe the lamentation of women and men instead (including group wailing) (Goltsev, 1933:92,93; Dadwani, 1973:12-14). As S. Bolle-Zemp states (and as we witnessed ourselves during our own field work) "the zär are performed throughout the funerary ceremony until the setting of the sun, when the deceased will be buried in the cemetery" (Bolle-Zemp, 1994:49).

Such meagre and variable data about zär, in combination with its peculiar musical structure and vague 'text,' makes it difficult to fully comprehend it.

Thus, based on such diverse pieces of evidence, the current state of discussion on this multifaceted and sophisticated phenomenon can be summarized as follows: a) it is not considered an emotion-driven spontaneous mourning behavior such as the planctus and is more something like the discourse which is a more framed, rationalized, and stylized expression of grief or a "lyrical resolution of suffering" (Lloyd, 1980: 407). Instead, zär is a clearly structured polyphonic dirge 'sung' by "professionals." b) The emotional outreach and impact of zär, based on ethnographical sources and our experience in the field, is considered controversial. For some, zär sounds like a festive hymn (Paliashvili, 1909),24 for others its musical content can be extremely mournful and/or full of mysticism and, therefore, people avoid "singing" it at any other time except at a funeral; ${ }^{25}$ D. Kovalevskiy compares hymn-type repertoire (including zär) to a "wolf's howl" and considers it a remnant of the ancient stage of a human evolution (Kovalevskiy, 1930: 131). c) The

\footnotetext{
22 'Way!' can also be written as 'wai!', depending on how it is articulated during 'singing.'

${ }^{23}$ It is believed that the deceased was 'happy,' which means that his entire family survived his death and thus he never suffered the loss of younger family members.

${ }^{24}$ M. Bray describes zär as an "ancient song ...supporting the soul's transition after death" (Bray, 2011)

${ }^{25}$ During field work in 2016, our informants refused to perform zär inside one's house and we had to go away from the village and find a deserted place to record them.
} 
original purpose of zär, being a part of the Svan singing repertoire, according to Georgian scholars (Arakishvili, 1950: 21; Chijavadze, 1991: 18,19, Mzhavanadze, 2018), has an ancient origin, and thus remains vague. That the word zär does not seem to have the mourning connotation until the 17-18th century complicates the matter even more. Furthermore, the fact that today zär is organically integrated into the funeral rite contradicts some ethnographical accounts, according to which zär would be performed only for the 'happy' deceased (Arakishvili, 1950: 23l; Akhobadze, 1957: 21). ${ }^{26} \mathrm{~d}$ ) The name zär is also common for the mourning ritual repertoire in other parts of Georgia (zari in Georgian, ${ }^{27}$ azar in Abkhazian) ${ }^{28}$, however, a complex comparative study is needed to reveal if they are related. ${ }^{29}$ In this respect, especially interesting are the hymn-type zaris from Guria, Samegrelo, and Rach'a. ${ }^{30}$ e). It is a three-part chant, the musical language of which raises interest about its relationship to other hymn-type repertoire in Svaneti. f) It is a chant without text, and its vocabulary is built with vowels and utterances/exclamations. This makes it difficult to explain some earlier references claiming that zär was sung with text, which served as a farewell 'speech' about the deceased's deeds and personality. However, considering the musical peculiarities of zär, conventional verbal text seems impossible to fit in.

Hence, the genesis of zär and its true nature remains somewhat mysterious and inexplicable. Despite zär being a subject of scholarly interest, there is no monographic study made on it, and only few investigations have been conducted, which will be reviewed in the following chapter.

\footnotetext{
${ }^{26}$ Today the same function (of chanting for a 'happy' deceased) is only attributed to another hymn-type 'song,' k'viria.

${ }^{27}$ In Rach'a, apart from zari, another form of lament is zruni, which is a lament with text about the deceased. The song draws a special interest because it is sung in only two Upper Rach'an villages: Ghebi and Glola, which were historically inhabited by Svans.

${ }^{28}$ Accounts on azar are not consistent. Sh. Inal-ipa, an Abkhazian ethnographer and historian, points to the significance of a mourning song azar in Abkhazian people's ethnography (Inal-ipa, 1965: 610, 611). However, a song with the same name is sung before horse races (Songs of Abkhazia and Adzharia, 1993). Also, "a special kind of keening, called azar, is performed when a young boy dies. Male laments of this kind can be performed with apkhiartsa accompaniment" (ibid). In the records, however, the men's groupkeening "before the funeral starts" is named as lament instead of azar although the same song is part of a bigger composition called azar (ibid). The same song with the name of azar is described by V. Akhobadze (1956) as a mourning song.

${ }^{29}$ It should be noted though that the text of most keening repertoire of all types including zari (or Svan zär) employ the utterance 'wui' or 'wai' which has a mourning connotation.

${ }^{30}$ Male group mourning tradition in Tusheti and Khevi are known as respectively dala and dadai, adai. They represent a responsorial form between a soloist (lamenting with a text) and a choir (responding with utterances in unison).
} 


\section{Literature review}

Zär already drew the attention of professional and amateur musicians as early as the end of the 19th and beginning of the 20th century. For a long time, however, only general reflections of $z a ̈ r$ have been made. Until a few decades ago, this form of traditional musical expression has never been the subject of a scrutinized study.

The mainstream scholarly thought on zär is that its roots go back to ancient times. The arguments for this assumption are mainly derived from its musical syntaxes, which include: a narrow span of voice movements, utterance-based musical phrases, syllable and vowel-based 'text,' a combination of simple two and three-part harmonic segments, step-wise movement of voices, sharp alteration of mode or neutral mode, performing style (antiphonal, glissandi, etc.), as well as the sacred context and poly-functionality (cult of the dead) and exclamations, and two-part segments, which are believed to be remnants of the stadial development of polyphony, etc. (Karbelashvili, ${ }^{31} 1898$; Arakishvili, 1950: 9; Chkhikvadze, 1948: 29; Aslanishvili, 1954: 87; Chokhonelidze, 1973; Chijavadze, 1991: 19; Rosebashvili, 1982: 45, 46; Baiashvili, 2012).

Some authors have explored semantic and functional aspects of the chant. N. KalandadzeMakharadze (2005) hypothesizes that zär would originally be related to men's group outcries, which gradually developed into refined chant, gaining a magical form of semantics or a means of (signal-giving) communication. ${ }^{32}$ Furthermore, she assumes that being an exclusively men's group repertoire, zär could be considered to belong to the group of work songs, particularly to the type of work which demands joint power, such as lifting and carrying (dragging) heavy items. So, she suggests zär originally to have been a work song (Kalandadze-Makharadze, 2005: 170 -171).

The "non-semantic" vocabulary of zär is a primary argument for D. Kovalevskiy (1930) to assume that it is an ancient form of music making. According to the author, a working process demands repetitive movements. Repetition naturally requires a rhythm which is provided by men via utterances which themselves can be considered as singing.

\footnotetext{
${ }^{31}$ Karbelashvili, though, points to the zari in general without specifying the region.

32 N. Kalandadze-Makharadze, discussing possible semantic meaning of the utterances of zär suggests that they can be magic instruments to communicate with the deceased, scare away death, and "wake him up" (Kalandadze-Makharadze, 2005: 159).
} 
In contrast to the theory of ancient origins of zär, T. Gabisonia (2012) suggests it to be closely related to and influenced by Georgian church music. He believes that zär is a paganized (simplified) version of Georgian church music, which he assumes to have been sung during a liturgy in Svaneti in the Middle Ages. He claims that due to historical hardships, the liturgical practices gradually stopped in Svaneti, but people kept the chants in memory trying to employ them in non-liturgical sacred ceremonies. He furthermore assumes that during this long process only bits of words would survive in the form of vowels and syllables. These would be coupled with fragments of the music representing a compilation of the phrases, which are difficult to perceive as accomplished musical image(s). The author sees compositional similarities between zär and church chants (e.g. "melodic continuum" held on with one syllable) as one of the arguments for this connection (Gabisonia, 2012). Long before this, Z. Paliashvili (1909) believed that the hymn simply deformed over time, and that the remaining syllables are the remnants of the text, which were forgotten, and therefore it would be difficult to grasp the text. However, he does not make a notice of church music here. ${ }^{33}$

S. Bolle-Zemp was the first to investigate the musical structure of zär in relation to the 'text' (Bolle-Zemp, 1994; 1997; 2001). She was also the first to apply quantitative methods to the analysis of zär in order to improve the interpretation of 'non-semantic' text and explain some musical peculiarities of zär. Her interdisciplinary approach involves the attempt to understand the ethnographical context of the chant and the investigation of its linguistic and musicological aspects. Employing the tools accessible at that time, she processed the chant through sonographic images and analyzed the musical content of the verbal 'text'; explored all the possible references of the utterances employed in zär, and visualized the results in the form of sonograms. Based on the results of her multi methodological analysis, S. Bolle-Zemp suggests a strong correlation between words and music. She hypothesizes that the verbal text takes a leading role in shaping the musical structure of zär. She assigns semantic importance to the core utterance woi, arguing that as an utterance of mourning connotation, it lies at the root of several vocal formulas of the chant. In her view, 'singers' emphasize human emotions such as pain, dignity, etc. by modifying the sound characteristics of spoken language, e.g., through the

\footnotetext{
33 Please note that A. Dirr's (1914) article on Svan music is a condensed version of Paliashvili's collection of Georgian (including Svan) songs published in 1909. Therefore, the review of the songs as well as the notated transcriptions belong to Z. Paliashvili (1909).
} 
formation of vowels and consonants in different ways, by manipulating the interjections, and by stylizing the expressions of the spoken language through certain vocal processes (valorization, descending glissandi, nasalization). In her view, the structure of the movement of voices, the duration of a sound, the sequence of concomitants, and the interrelationship of consonant and dissonant chords is greatly conditioned by the 'text,' which coordinates the musical process (Bolle-Zemp, 1997; 2001).

In her prior work Mzhavanadze (2018) investigated the ethnological context of zär, and explored etymological, linguistic, and musicological aspects via manual analysis of both archive recordings as well as the variants documented together with F. Scherbaum during the field work in Svaneti in 2016 (Scherbaum \& Mzhavanadze, 2018). This included a comparative review of the musicological characteristics of the chant and the attempt to understand the relationship between the musical forms and the language of Svan zär and of dirges from Racha (zruni), Apkhazeti (azari) and from Guria and Samegrelo (zari) (Mzhavanadze, 2018: 175-233).

This study has developed a wide range of hypotheses, some of which include the following: a) It was suggested that the powerful cult of the dead, preserved in Svaneti until the present, was to be honored through a religious hymn addressed to the deity of the land of souls. ${ }^{34}$ b) It was also suggested that the utterances such as "wo," "ieha," as well as "dide," "dai," etc. belong to the evocation, supplication, and glorification vocabulary (Mzhavanadze and Chamgeliani, 2016), but are also used in other hymn-type Svan songs. This would support the theory of a religious origin and function of $z \ddot{a r} .^{35} \mathrm{c}$ ) Svan zär was interpreted to be of local origin, since its musical characteristics are not similar to zaris from other parts of Georgia. d) It was observed that the musical structure of zär is built and governed by vertical (harmonic) movements, rather than the melodic (horizontal) line. e) Both theories of the stadial (evolutionary) development of Svan polyphony have also been challenged, in favor of the hypothesis of polyphonic vertical structure, which should be ontogenic. g) The observed dominant position of fifths and

\footnotetext{
${ }^{34}$ R. Gujejiani, Chamgeliani, Tsintsadze, and Cheishvili in the study of a Svan hymn k'wiria say that "zär in Svaneti meant not only mourning/weeping but a hymn" (Gujejiani et al., 2011:65), however, they do not refer to the primary sources of this information.

35 This hypothesis also is supported by the results of the manual analysis of a variant of zär recorded in Lakhamula village in 1928. Despite the poor quality of the chant, one can detect the usage of the glorification vocabulary such as 'didäb' (meaning "glory to"), which is a clear evidence that the chant had a religious hymn connotation (Mzhavanadze, 2018:192).
} 
fourths, as well as unison, provokes a hypothesis that zär's polyphonic tissue realizes/ manifests overtone intervals and triggers a theory of 'overtone polyphony.'36

It is worth mentioning that most of the prior studies on zär represent logical interpretations and reflections derived from general observations of the chant. With the exception of S. Bolle-Zemp's study, which is exceptional with regard to the transparency and reproducibility of her research methodology, most of the older studies are not based on the analysis of contextual material and/or in-depth scrutiny. However, the analysis of only one example of zär in S. Bolle-Zemp's work limits the generalizability of her results to other variants of the chant. Besides, although the general quality of S. Bolle-Zemp't recordings is good, the recordings of that time do not allow an analysis of the acoustical properties of individual voices because of the unresolved problem of separation of individual voices within polyphonic field recordings. ${ }^{37}$

\section{A new corpus of zär recordings}

In the present study, we aim to contribute to the discourse on zär from a new (computational) perspective and with a greatly enlarged dataset, which we collected during a three-month field expedition to Upper Svaneti and Svan eco-villages in 2016 (Scherbaum \& Mzhavanadze, 2018; Scherbaum et al., 2018; Scherbaum et al., 2019). The newly collected data consist of 11 recordings of 6 different variants of zär. The recording locations and the locations of origin of the different variants are shown in Figure 1 with red solid circles and black stars, respectively. The technical quality of the data is good to excellent. All recordings were done as multi-media recordings, in which a high resolution (4K) video stream is combined with a stream of 3-channel headset microphone recordings (one for each voice group), a stream of 3-channel larynx microphone recordings (one for each voice group as well), and a conventional stereo recording. The systematic use of larynx microphones, which to our knowledge has never been done before in ethnomusicological field expeditions, was motivated by the results of a pilot study in Upper Svaneti in 2015, which showed that larynx microphones allow the

\footnotetext{
${ }^{36}$ Comparative study of different zär reveals a tendency of attempts to widen the melodic boundaries in more advanced variants of the chant in which contours of tunes can be grasped. This results in production of sixths, seventh, etc.

37 This problem becomes also acute when focusing on retrospective study of the chant to reconstruct the stages of its development and changes. The quality of older archive recordings is often critically poor and sometimes does not allow even a minimal manual processing.
} 
undistorted documentation of the contribution of each singer, while all of them are singing together in their natural context (Scherbaum et al., 2015). In addition, larynx microphone recordings were also shown to contain essential information in relation to a singer's voice regarding pitch, intonation, timbre, and voice intensity, which allows the application of computer based methods to document and analyze vocal music of the oral tradition in new ways, e. g. to perform computerized pitch-analysis techniques to document the pitch tracks (including the microtonal structure), to study the pitch inventory and scales used together with the interaction between singers (Scherbaum et al., 2015; Scherbaum 2016).

All the recordings of the 2016 field expedition have been made publicly available and can be accessed either through the open access long-term archive at the University of Jena, which also hosts the field report and the meta data (https://lazardb.gbv.de/search; see Scherbaum et al., 2018 for details), or through the research repository at the University of Erlangen (https://www.audiolabs-erlangen.de/resources/MIR/2017-GeorgianMusic$\underline{\text { Scherbaum see Figure 2) }}$ 38.

38 User name and password can be obtained through the second author (fs@geo.uni-potsdam.de). 


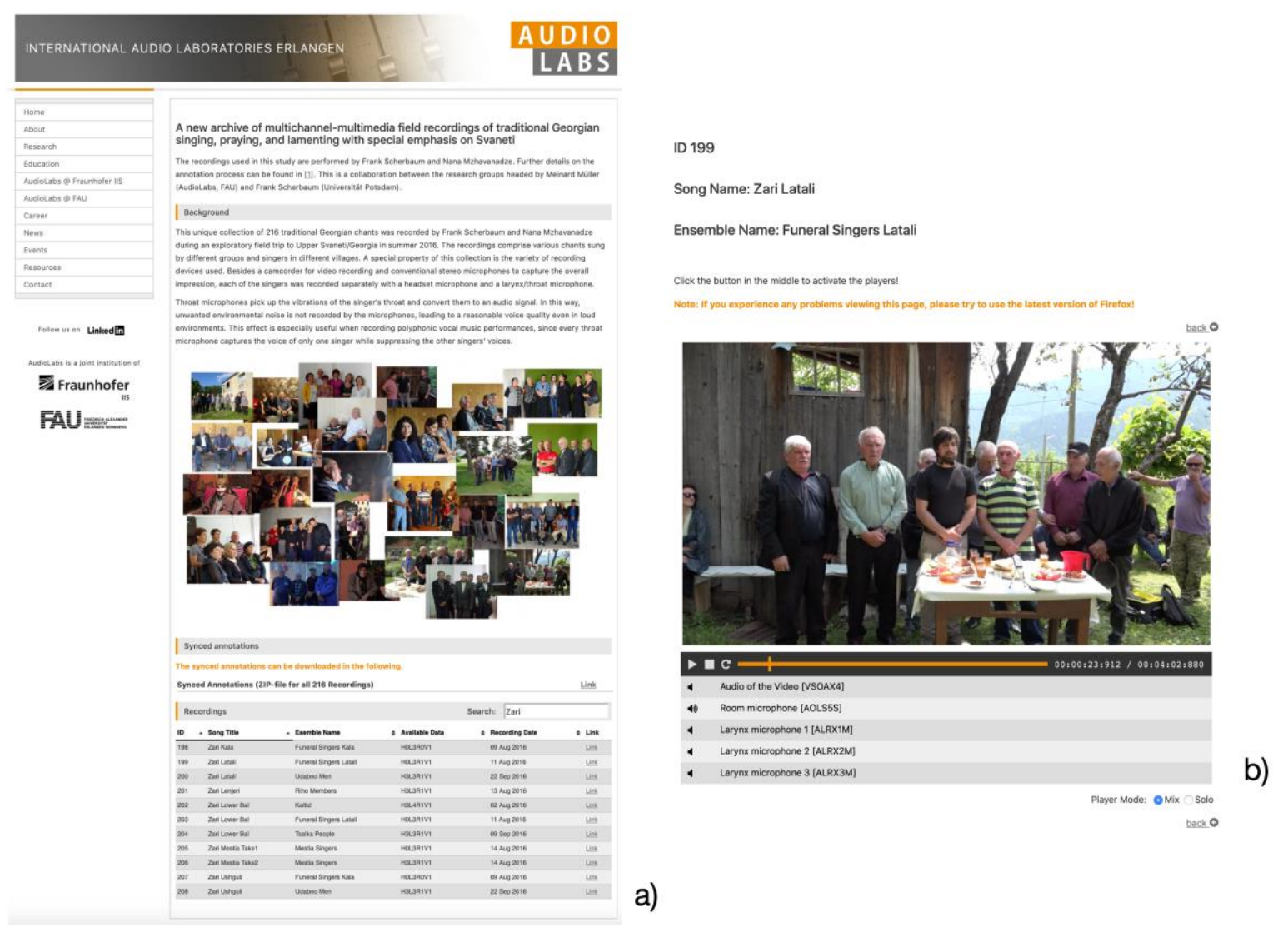

Figure 2. Web interface of the research repository hosted at the University of Erlangen, which allows access to the new corpus of zär recordings (audio-, video-, and larynx microphones). a) top level menu showing the meta data of all zär recordings in the repository. b) For an individual selected performance, here for ID 199, one can play back individual tracks or combinations thereof together with the video of the performance.

The 11 recordings of funeral chants were made in different contexts (cf. Figure 1 and 2). Four of them were documented during actual funerals: two (the Lower Bal and Lat'li variants) at the funeral in the village of Lat'li, and the other two (K'āl and Ushgul variants) in the village of K'āl. The rest were recorded during conventional recording sessions.

Apart from the Upper Svaneti area, we also visited and worked with the eco-migrant Svan communities of Ts'alk'a and Udabno, outside Svaneti, near the capital of Tbilisi (Figure 1). These recordings may become especially precious because the villages are populated by eco-migrant Svans who migrated from different communities of Upper Svaneti a few decades ago. The analysis of these recordings, we believe, can help to retrieve significant information about the changes (if any) in the repertoire (including zär) and their 'lives' after they have 'dislocated' from their homes to a new geographical and social context. 
Our goal in the project was broad, and apart from aiming to document the musical life of modern Svans, we put effort into understanding the wider context of the musical repertoire. Therefore, all the recording sessions were accompanied by extensive interviews with the tradition-bearers. They (e.g., Murad Pirtskhelān) informed us that in Upper Svaneti they have eleven variants of zär. However, when asked to name them, they could only remember/list ten variants of zär, out of which two belong to the Lower Bal area (the Lower Bal and Lakhamula variants), whilst the other eight variants are from Upper Bal villages: Lat'li, Lenjār, Mest'ia, Mulākh, Ipār, Ts’virmi, Ieli, and Ushgul. ${ }^{39}$

From the interviews with the tradition-bearers during the fieldwork we made some interesting observations:

First, the fact that zär has been conducted at every funeral over the last few decades contradicts some older accounts, which mention zär as the chant performed exclusively for the 'happy' deceased. The locals appeared not to be aware of this historical change. This allows us to assume that over time, human understanding of $z \ddot{a} r$ and its application has been re-thought and revised. Or, alternatively, one could postulate that the term zär could also denote another type of funeral music that has lost its importance and, therefore, could not survive until the present. Conversely, it could mark another form of keening, similar to the Eastern Georgian tradition, allowing the recitation of verbal texts improvised by a mourner.

At the very first recording session of the chant, we faced the problem of labelling zär. It turned out to be difficult to find the appropriate/relevant vocabulary and expressions to make notes about it. This raised the question of how Svans understand the concept of music and what zär means to them in this respect. In the Svan language, there are two music-related expressions/words related to singing and chanting: moøুn̄క̄m ${ }^{40}$ (lighrāl a song) and zs

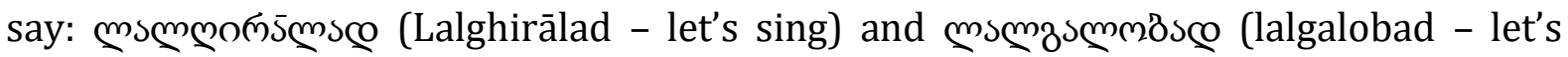

\footnotetext{
${ }^{39}$ Out of these variants we have recorded zärs from Lower Bal, also Lat'li, Lenjār, Mest'ia, and Ushgul (K'āl and Ushgul zär are considered to be the same variant) communities (see Figure 2). It was reported to us that there is nobody left to do zär from Lakhamula village. As to Məlākh community, due to objective reasons, we missed a funeral there and, therefore, could not document the zärs from Məlākh and Ipār communities which, according to our information, had been chanted there.

${ }^{40}$ It should be noted here that the word for supplication in Svan is very similar to that of a song: mos $\overline{2} \overline{\mathrm{m}} \overline{\mathrm{m}}$

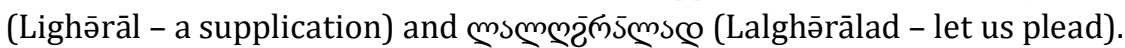


chant). Neither of the terms are used in relation with hymn-type songs including zär and they never say: let's sing/chant zär (or other sacred hymn-type 'songs'). Instead, for such

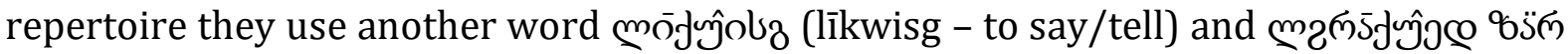
(lərākqwed zär - let's say/tell zär). ${ }^{41}$ Svans, therefore (although they attribute the mourning connotation to the zär), never use the keening terminology in relation to it. Based on these observations, in order to emphasize its funeral function, on the one hand and, on the other, to demonstrate its hymnic nature, we have made a choice in favor of the conditional use of the term 'dirge': a 'dirge' being 'chanted' (or sometimes 'done') to describe zär.

As mentioned above, zär is seen to have a very sacred connotation and the locals refuse to sing it anywhere else except a funeral. Therefore, while it was easier to make recordings of zär in its natural context during the funerals in Lat'li and K'āl, in other places we had to compromise and find solutions to record it out of context. For example, to record the zär from Mest'ia (IDs 205 and 206 in research repository, see Figure 2) we managed to gather three men (Khvicha Chartolān, Valeri Khergiān, and Nuri Khergiān) from the Mest'ia community and headed off to the village of Zargāsh to find Baju Rat'iān, without whom it would be impossible to record it. He refused to do the zär, for it is believed to be a bad sign to 'perform' it in someone's house unless someone had died there. Thus, despite the rain, we had to go out of the village with all the recording equipment and record them in a tiny hut without walls, temporarily built for the road workers by the forest. It seems that although the zär musically and verbally (only vowels and utterances) sounds similar to some other Svans hymn-type repertoire, the musical features themselves do not carry the distinguishing meaning for the locals. This shows the importance of a comparative analysis, which can help with disclosing both differences and similarities between the zär and these songs and finding the aspects, to which the locals attribute a special mourning connotation.

Another phenomenon that drew our attention is related to the perceptional aspect of $z a ̈ r$. For a neutral listener it feels difficult to grasp a structure and tune. The deficiency of verbal language, blurred/free rhythm, the absence of explicit meter, and the elusive/uncatchable tune make it difficult to describe what helps the performers to

${ }^{41}$ It is important to note here that the same expression is also used regarding sacred prayers. 
memories and synchronize it in three parts. Furthermore, it raises the question about how, without clear mnemonic tools, would it normally be learnt and taught.

Our experience during field work made us assume that being a zär singer is a kind of an unofficial profession, because only a few people can sing it, and it becomes more and more difficult to find those who can still do it. Gradually, old singers die, and those who still pay tribute to the dead from their villages and communities painfully admit that after their death, there will be no one left to do zär for them. Baju Rat'iān from Zargăsh told us, that their group is often invited by families of the deceased to do zär, and therefore, sometimes they travel hundreds of kilometers to remote (eco-migrant Svan villages) to chant there at funerals. As we understand, the more variants of zär are performed at the funeral, the more honor it is for the family. It is especially important to offer the zär from the community from where the deceased comes. This is why Baju and his fellow singers, for example, cover dozens of kilometers to pay tribute to the deceased who had migrated from Mest'ia to another part of the country where no one can do the zär.

The issue of the difficulty of training/teaching zär, as mentioned above, was triggered by the problems we encountered during fieldwork. When we asked the famous song master and leader of the renown 'Riho' choir Islam Pilpān to perform zär from the Lenjār community where he comes from, he said that it was impossible because Robinzon Shuk'wān (76), the only person who could do the upper voice, was absent.

We had no other choice but to go to the village of Lemsia (Lenjār community) to find and bring the singer (see ID 201 in the research repository). This made us curious to ask the singers to do individual parts of the dirge. They could not do it, and said it was difficult. Although Islam Pilpān was a long-time teacher and the most prominent living master of the Svan traditional repertoire, it was difficult for him to sing a single voice without his fellow singers. The answer to our question to both Baju Rat'iān and Islam Pilpān about how Svans would normally learn zär was very similar. They said one should hear/listen to it from early childhood throughout one's life. ${ }^{42}$

\footnotetext{
${ }^{42}$ This does not apply to the methods which we can employ today. Via recordings or transcriptions one can learn zär despite its peculiar complexity. Here we emphasize the traditional ways of learning/teaching zär in the past, when there were no recordings or notated transcriptions.
} 
Apart from the above-mentioned observations, we noticed that the tendency of gradual and consistent pitch shifting throughout the zär reveals differing intensities, and the degree of the shift varies from group to group. This is detailed in two other related articles (Scherbaum \& Mzhavanadze, 2020; Mzhavanadze \& Scherbaum, 2020).

As mentioned earlier, the question of the interrelations/interconnections of the Svan zär to the zari from other parts of Georgia (Samegrelo, Rach'a, Guria) is also of vital importance for understanding crossing points (if any) and differences, discerning the aspects they share, and estimating the degree of inter influences (if any). This may help shed light on the genesis and historical development of the chant. It is possible to conduct a comparative analysis of certain aspects, such as melodic formulae, cadences, harmonic inventory, etc. with the help of notated examples of the zaris. Despite the fact that certain explicit acoustical analyses of the recordings were made long ago, these can still reveal general tendencies, and help sketch the contours of the basic general framework of the chant.

\section{Conclusions}

Our aim has been to offer a holistic study of the phenomenon of $z a ̈ r$, as found in the region of Svaneti. Our in-depth contextual description of zär, including our opening "thick description" of the context in which zär is performed, has helped better interpret the results of our interdisciplinary computational and musicological analysis. Consideration of the geography of Upper Svaneti has also helped for example, to reveal how the complexity of the musical form of different variants of dirge varies systematically along the course of the Enguri valley (Scherbaum \& Mzhavanadze, 2020).

The study of the cultural life and history of Svaneti and the Svan people shows that the powerful religious beliefs of the Svans have a strong influence on the everyday life of the local population and condition the features of their culture. Moreover, the heterogeneous ethnographic evidence on Svan rituals, and especially, on zär and its musical and phonetic features make the origin and ontogenetic function of zär controversial and give rise to discussions on this topic.

Critical processing of the broader data in the present study suggests that originally, the dirge may have been a sacred ritual hymn, which was later incorporated into funerary 
rites. This is confirmed by the analysis of the term ' $z a ̈ r$, ' common in other parts of Georgia. Etymological research suggests that this term acquired a mournful connotation at a later stage of history, and its musical 'language' reveals a close connection with hymn-like songs considered to be of pre-Christian origin. Its peripheral vocabulary is also shared with other hymn-like songs.

In addition to the review of historical contextual data, the large corpus of the multimedia field collection (2016), which includes 11 recordings of 5 variants of the zär, allowed for a state-of-the-art analysis. Interviews with tradition-bearers revealed contradictions between the metadata collected in the field and the historical and ethnographic accounts. Thus, it can be assumed that at least the ritual function, the practical purpose, and both the emic and etic understanding of the zär have undergone some changes over a not-solong historical period.

Finally, the observation of the music-making process during the recording sessions of the different groups allowed us to put forward several important hypotheses regarding musicological features. For example, it was almost impossible for the singers to 'sing' individual parts of the dirge without the participation of other voices, which served as one of the arguments in favor of the hypothesis that zär is not the result of the evolutionary (stadial) development of three-part polyphony, but represents an example of an ontogenetically three-part musical phenomenon. In addition, the well-known feature of Georgian music of successive pitch shifts throughout the song does not appear to be systematic and consistent, at least in the case of zär recordings. Analysis of recordings of the same zär variant by different groups revealed large differences in recordings in this respect.

Although we have, as mentioned above, attempted to exhaust the topic of zär through a multi-layered and comprehensive study, we believe that a further comparative study of the dirge would be very useful in identifying its links with other zaris, especially from neighboring areas of Georgia.

But before we proceed to broader research goals that include the comparative analysis of $z \ddot{r} r$ with other repertoire, we believe this phenomenological research is of paramount value. To understand the musical grammar of this special musical form, which is supposedly attributed to a fundamental form of social behavior, such as funeral ritual, is 
of critical importance. To this end, we have therefore conducted acoustic, musicological, and phonetic analysis into this unique musical legacy, the results of which are presented in: Scherbaum and Mzhavanadze (2020), Mzhavanadze and Scherbaum (2020) and Scherbaum and Mzhavanadze (2021).

\section{Acknowledgement:}

Nana Mzhavanadze would like to offer her grateful thanks to Madge Bray, whose deep respect for the ancient cultural musical tradition and those indigenous elders who carry its legacy in Svaneti, served to create the early conditions for her, which made this research possible.

\section{REFERENCES}

Abuladze, Ilia. (1972). Dzveli Kartuli Enis Leksik'oni (Dictionary of Old Georgian Language). Tbilisi: Metsniereba.

Akhobadze, Vladimer. (1956). Apkhazuri Khalkhuri Simgherebi [Abkhazian Folk Songs]. [Musical score]. Tbilisi: Tbilisi State Conservatoire.

Akhobadze, Vladimer. (1957). Kartuli (Svanuri) Khalkhuri Simgherebi [Georgian (Svan) Folk Songs]. [Musical Score]. Tbilisi: Teknika da Shroma.

Arakishvili, Dimitri. (1950). Svanuri Khalkhuri Simgherebi (Svan Folk Songs). Tbilisi: Khelovneba.

Arakishvili, Dimitri. (1954). Dasavlet sakartvelos khalkhur simgherata k'ilos tsq'oba (Mode structure of songs of western Georgia). Tbilisi: Khelovneba.

Aslanishvili, Shalva. (1954). Nark'vevebi Kartuli Khalkhuri Simgherebis Shesakheb (Essays on Georgian Folk Songs). Vol. I. Tbilisi: Khelovneba.

Azikuri, Nanuli. (1986). Mgosanni glovisani (Poets of Sorrow). Tbilisi: Metsniereba.

Azikuri, Nanuli. (2002). Khmit Nat'irlebi (Lamentation with voice). Tbilisi: Kavkasiuri sakhli. 
Baiashvili, Ketevan. (2012). “Sitq'visa da Hangis Urtiertoba Glovis Nimushebshi” (The relationship Between a Tune and a Word in Georgian Mourning Motifs). Unpublished manuscript.

Bardavelidze, Vera. (1939). Svanur khalkhur Dgheobata K'alendari. Akhalts'lis Tsik'li. (Calendar of Svan folk festivals. New Year's cycle). Tbilisi: Georgian branch of the USSR Academy of Sciences.

Bardavelidze, Vera. (1941). Kartvelta udzvelesi sarts'munoebis ist'oriidan: ghvtaeba Barbar-Barbar (From the history of the ancient religion of the Georgians: the deity of Barbar-Barbar). Tbilisi: Georgian Academy of Sciences.

Bolle-Zemp, Sylvie. (1994). Géorgie: Polyphonies de Svanétie (Georgia: Polyphony of Svaneti). [Liner notes]. [CD]. Paris: Le Chant du Monde: Diffusiona Harmonia Mundi.

Bolle-Zemp, Sylvie. (1997). "Mehrstimmige Wehrufe? Ein Begräbnisgesang aus Swanetien" Georgica: (Multi-Voiced Laments? A Funeral Chant From Svaneti). Georgica. 20:134-148.

Bolle-Zemp, Sylvie. (2001). "Khmovnebi da Ak'ordebi. Simghera Zemo Svanetshi" (Vowels and Chords. Singing in Zemo Svaneti). Sasuliero Da Saero Musikis Mravalkhmianobis Problemebi (Problems of Polyphony in Sacred and Secular Music). Ed. Rusudan Tsurtsumia: pp. 292-303. Tbilisi: Tbilisi State Conservatoire.

Bray, Madge. (2011). "Echoes of the ancestors life, death and transition" Caduceus: 81:69.

Chamgeliani, Madona; Khizanishvili, Manana. (2019). Earthly and Sacred Universes (Svaneti). Ketevan Margiani (Ed.). Tbilisi: Artanuji.

Chartolani, Mikheil. (1977). “Svanetis Mat'erialuri da Sulieri K'ult'uris Shests'avlisatvis” (For the Study of Tengible and Spiritual Culture of Svaneti). Svaneti 1, Masalebi Mat'erialuri da Sulieri K'ult'uris Shests'avlisatvis (Materials for the Study of Tengible and Spiritual Culture), Ed. Mikhail Chartolani: pp. 6-16. Tbilisi: Metsniereba.

Chelidze, Gizo. (1987). Kartuli khalkhuri Drama (Georgian Folk Drama). Tbilisi: Ganatleba. 
Chijavadze, Otar. (1991). Svanuri khalkhuri simgheris adgili kartul khalkhur shemokmedebashi (The place of Svan folk song in Georgian singing folklore). Annual Academic Work. Tbilisi: Tbilisi State Conservatoire.

Chimakadze, Niko. (1913). "Tavisupali Svaneti" (Free Svaneti). Dzveli Sakartvelo (Old Georgia). Ethnography: Ethnographical Esseys. Ed. Ekvtime Takaishvili: pp. 1-36. Tbilisi: Electric printer of Spiridon Losaberidze.

Chkhikvadze, Grigol. (1948). Kartveli Khalkhis Udzvelesi Samusik'o Kultura (Ancient Musical Culture of the Georgian People). Tbilisi: Musical Foundation of the Georgian SSR.

Chokhonelidze, Evsevi. (1973). “Diat'onur K'ilota Sak'itkhebisatvis Kartul Khalkhur Musik'ashi" (On Diatonic Modes in Georgian Folk Music). Sametsniero Shrombi (Scientific Works). Eds. Shaverzashvili Alexandre and Tumanishvili Ketevan: pp. 127-143. Tbilisi: Tbilisi State Conservatoire.

Chokhonelidze, Nineli. (2016). “Zar-Pudziani Omonimuri Tsalebis Ist'oriisatvis Kartulshi" [For the History of the Homonymous Parts With Root of "zar" in Georgian]. Arnold Chikobavas sak'itkhavebi [Studies by Arnold Chikobava]. [Paper presented at Academic Session dedicated to A. Chikobava studies on April 19-22, 2016, Tbilisi, Georgia). (pp. 78-80). Tbilisi: Arn. Chikobava Institute of Linguistics.

Dadwani, Platon. (1973). "Svanetis chveulebani" [Customs of Svaneti]. Etnograpiuli Tserilebi Svanetze [Ethnographic Records on Svaneti]. Tbilisi: Sabch'ota Sakartvelo.

Dirr, Adolf. (1914). "Neunzehn Swanische Lieder" (Statt Eines Referates.) (Nineteen Svan Songs). Anthropos, 9(3/4): 597-621. Retrieved from www.jstor.org/stable/40443095

Eristov, Rapiel. (1898). Zamet'k'i o Svanet'ii (Notes on Svaneti). Tiflis: Tipografiya M. Sharadze.

Erkvanidze, Malkhaz. (2014). “Kartuli Saek'lesio Galobis Gadaghebis Ist'oria da Kartuli Samusik'o Sist'ema" (History of Recording Georgian Church Chants and Georgian Music System) PhD. Dissertation, Georgian Technical University, Tbilisi: Georgia.

Firth, Raymond; Mclean, Mervyn. (2006). Tikopia Songs. Poetic and musical art of a Polypnesian people of the Solomon Islands. Cambridge: Cambridge University Press. 
Gabisonia, Tamaz. (2012). "Krist'ianuli K'vali Svanur himnur simgherebshi” (Christian Traces in Svan Hymn Songs). Arhaic Elements in the Ethnic Culture of Highland Georgia. Tbilisi: Unpublished.

Gabliani, Egnate. (1927). Tavisupali svaneti (Free Svaneti). Tbilisi: Sakhelgami.

Gasviani, Geronti. (1991). Nark'vevebi Shua Sauk'uneebis Svanetis Ist'oriidan (Essays from the History of Medieval Svaneti). Tbilisi: Metsniereba.

Geertz, Clifford. (1973). "Thick Description: Toward an Interpretive Theory of Culture", The Interpretation of Cultures: Selected Essays. New York: Basic Books. Retrieved from http://cscs.res.in/dataarchive/textfiles/textfile.2009-08-14.2117562205/file

Giorgadze, Dali. (1987). Dak'rdzalvisa da glovis ts'esebi sakartveloshi: tush-pshavkhevsuretis etnogr. masalis mikhedvit (Funeral and Mourning Rules in Georgia: According to Tush-Pshav-Khevsureti Ethnographic Material). Tbilisi: Metsniereba.

Goltsev, Viktor. (1933). Savane: Zapisi o Verkhney Svanetii (Savane: Records of Upper Svaneti). Moscow: Moskovskoe Tovarishchestvo Pisateley.

Graham, Laura. (1984). "Semanticity and Melody: Parameters of Contrast in Shavante Vocal Expression", Latin American Music Review / Revista de Música Latinoamericana. 5(2): 161-185.

Gujejiani, Rozeta; Chamgeliani, Madona; Tsintsadze, David and Cheishcili, Giorgi. (2011). "'K'viria'" Svanetis T'raditsiul Q'opashi" ("'K'viria'" in the Traditional Life of Svaneti). Svanetis Istoriis Purtslebi (Folios of History of Svaneti). Ed. Rozeta Gujejiani: pp. 62-69 Tbilisi: LTD 2000.

Inal-Ipa, Shalva. (1965). Abkhazy: Istoriko-Etnograficheskie Ocherki (Abkhazians: Historical-Ehtnographic Esseys). Sukhumi: Abgosizdat.

Javakhishvili, Ivane. (1928). "Kartvelta ts'armartoba" (Paganism of Georgians). Kartveli Eris Istoria (History of the Georgian Nation). Vol. 1, pp. 33-133. Tbilisi: Sil Tavartkiladze.

Javakhishvili, Ivane. (1938). Kartuli Musik'is Ist'oriis Dziritadi Sak'itkhebi (The Main Issues of History of Georgian Music). Tbilisi: Pederatsia. 
Jordania, Joseph. (2006). Who Asked the First Question? The Origins of Human Choral Singing, Intelligence, Language and Speech. Tbilisi: Logos

Jordania, Joseph. (2010). "Georgian Traditional Polyphony in Comparative Studies: History and Perspectives." Echoes from Georgia. Seventeen Arguments on Georgian Polyphonie. Eds: Rusudan Tsurtsumia and Joseph Jordania: pp. 229-249. New-York: Nova Publishers, Inc.

Kalandadze-Makharadze, Nino. (2005). “Glovis zari Kartvel Mamak'atsta T'raditsiul Mravalkhmianobashi" (The Funeral Zari in Traditional ale Polyphony). [The Second International Symposium on Traditional Polyphony]. Tsurtsumia, Rusudan and Jordania, Joseph (Eds). (pp. 166-178). Tbilisi: International Research Center for Traditional Polyphony of Tbilisi State Conservatoire.

Karbelashvili, Vasil. (1898). Kartuli saero da saek'lesio k'iloebi. Ist'oriuli mimokhilva (Georgian secular and church music. Historic review). Tbilisi: Stamba Iv. Kheladzisa.

Kaukhchishvili, Simon (Ed). (1955). Kartlis tskhovreba (Life of Kartli). V. 1. Tbilisi: Ganatleba.

Kazbegi, Aleksandre. (1974). "Elguja”. Rcheuli (Featured Works), pp. 7-173. Tbilisi: Sabch'ota Sakartvelo.

Kekelidze, Korneli. (1956). “Godebis Zhanri da Glovis Ts'esi Dzvel Kartul Literaturashi” (The Genre and Rules of Mourning in Ancient Georgian Literature). Etiudebi Dzveli Kartuli Literaturis Istoriidan (Essays on the history of Ancient Georgian Literature), V.1, pp. 198230. Tbilisi: Tbilisi State University.

Kenia, Marine. (2010). Upper Svaneti. Medeival Mural Painting. Tbilisi: G. Chubinashvili National Research Centre for Georgian Art History and Heritage Preservation.

Kondi, Bledar. (2012). Death and Ritual Crying: An Anthropological Approach to Albanian Funeral Customs. Berlin: Logos Verlag.

Kotetishvili, Vakht'ang. (1961). Khalkhuri p'oezia (Folk poetry). Tbilisi: Sabch'ota Mts'erali. 
Kovalevskiy, Boris. (1930). Strana snegov i bashen: Ocherky Svanskoiy Kulturi (Land of Snows and Towers: Essays on Svan Culture). Priboy: Pechatniy dvor.

Lamberti, Archangelo. (1938). Samegrelos aghts'era (Description of Samegrelo). Tbilisi: Pederatsia.

Lavrov, Leonid Ivanovich. (1950). "Rasselenie Svanov na Severnom Kavkaze do XIX v." [The settlements of the Svans in the North Caucasus before the 19th century]. Kratkie Soobshcheniya Instituta Etnografii AN SSSR [Short reports of the Institute of Ethnography]. X: 77-83. Moscow: Institute of Ethnography.

Lloyd, Albert. (1980). "Lament.” The New Grove Dictionary of Music and Musicians. Vol. 10. Ed. Stanley Sadie: pp. 407-410. London: Macmillan.

Love, Jakob W; Kaeppler, Adrienne. (2017). “Australia and the Pacific Islands.” The Garland Encyclopedia of World Music, Vol. 9. London: Taylor and Francis.

Milaneli, Don Dzhuzep'e Dzhudiche (Don Giuseppe Giudice Milanese). (1964). Ts'erilebi Sakartveloze. XVII Sauk'une (Letters About Georgia. Seventeenth Century). Tbilisi: Sabch'ota Sakartvelo.

Mzhavanadze, Nana. (2018). “Svanuri Sak'ult'o Rit'ualis Musik'ologiur-Antrop'ologiuri Asp'ekt'ebi" (Musicological and Anthropological Aspects of Svan Sacred Ritual) PhD. Dissertation, Ilia State University, Tbilisi: Georgia.

Mzhavanadze, Nana; Chamgeliani, Madona. (2016). "Svanuri Simgheris Asemant'ikuri T'ekst'ebis Sak'itkhisatvis" (Regarding the Problem of Asemantic Texts in Svan Songs). Kadmos 1987-8788. (8): 7-48.

Mzhavanadze, Nana; Scherbaum, Frank. (2020). "Svan Funeral Dirges (Zär): Musicological analysis". Musicologist. 4(2): 168-197.

Nizharadze, Besarion. (1962). Ist'oriul-Etnograpiuli Ts'erilebi (Historical and Ethnographic Essays), Vol. 1. Tbilisi: Tbilisi State University.

Nizharadze, Besarion. (1964). Ist'oriul-Etnograpiuli Ts'erilebi (Historical and Ethnographic Essays), Vol. 2. Tbilisi: Tbilisi State University. 
Orbeliani, Sulkhan-Saba. (1949). Sit/q'vis k'ona (Pile of words). Tbilisi: Sakhelgami.

Paliashvili, Zakaria. (1909). Kartuli Khalkhuri Simgherebis K'rebuli. Imeruli, Guruli, Rachuli, Svanuri da Kartl-K'akhuri [Collection of Georgian Folk Songs: Imeretian, Gurian, Rach'an, Svan and Kartl-K'akhetian]. [Musical Score]. Tbilisi: Kartuli Pilarmoniuli Sazogadoeba N5.

Phillips-Wolley, Clive. (1883). Savage Svanetia. Vol. II. London: R. Bentley.

Rosebashvili, Kakhi. (1982). “Kartuli Khalkhuri Simgheris Svanuri Dialekt'i: Zogierti Sats'eso da Rit'ualuri Simgheris Gankhilva" (Svan Dialect of Georgian Folk Song: Review of Some Ritual Songs). [Unpublished Annual work]. Tbilisi: Tbilisi State Conservatoire.

Rustaveli, Shota. (2017). Vepkhist'q'aosani (The night in the panther's skin). Retrieved from https://library.iliauni.edu.ge/wp-content/uploads/2017/03/40vephkhistqhaosani.pdf

Scherbaum, Frank. (2016). "On the Benefit of Larynx-Microphone Field Recordings for the Documentation and Analysis of Polyphonic Vocal Music" [Paper presented at the 6th International Workshop Folk Music Analysis on June 15-17, 2016]. (pp. 80-87) Dublin: Technological University of Dublin. Retrieved from https://arrow.tudublin.ie/cgi/viewcontent.cgi?article=1010\&context=fema

Scherbaum, Frank; Loos, Wolfgang; Kane, Frank and Vollmer, Daniel. (2015). "Body vibrations as source of information for the analysis of polyphonic vocal music" Proceedings of the 5th International Workshop on Folk Music Analysis, (The 5th International Workshop on Folk Music Analysis). (pp. 94-98), Paris: University Pierre and Marie Curie.

Scherbaum, Frank; Mzhavanadze, Nana. (2018). "A new archive of multichannelmultimedia field recordings of traditional Georgian singing, praying, and lamenting with special emphasis on Svaneti" LaZAR-Database. Retrieved from https://lazardb.gbv.de/

Scherbaum, Frank; Mzhavanadze, Nana. (2020). "Svan Funeral Dirges (Zär): Musical Acoustical Analysis of a New Collection of Field Recordings" Musicologist. 4(2): 138-167. 
Scherbaum, Frank; Mzhavanadze, Nana; Rosenzweig, Sebastian and Müller, Meinard. (2019). Multi-media recordings of traditional Georgian vocal music for computational analysis. Paper presented at the 9th International Workshop on Folk Music Analysis, England, 2-4 July, 2019.

Scherbaum, Frank; Mzhavanadze, Nana. (2021). "Svan Funeral Dirges (Zär): LanguageMusic Relation and Phonetic Properties" Musicologist, 5(1): 66-82.

Seeger, Anthony. (1981). Nature and Society in Central Brazil: The Suya Indians of Mato Grosso. USA: Harvard University Press.

Sikharulidze, Ksenia. (1970). Kartuli Khalkhuri Sit'q'viereba (Georgian Folklore). Tbilisi: Tbilisi State University.

Silogava, Valeri. (1988). Svanetis ts'erilobiti dzeglebi. Epigrapik'uli dzeglebi (Written Monuments of Svaneti. Epigraphic Monuments) Vol. II. Tbilisi: Metsniereba.

Songs from Abkhazia and Adzharia. (1993). [Liner Notes]. On Golden Fleece. Ethnic Series, Anthology of Music from the Caucasus - \#2. [CD]. Leiden: PAN Records.

Topchishvili, Roland. (2010). Sakartvelos Etnograpia/etnologia (Ethnography/ethnology of Georgia). Tbilisi: Universali.

Tsuladze, Apolon. (1971). Etnograpiuli Guria (Ethnographical Guria). Tbilisi: Sabch'ota Sakartvelo.

Uvarova, Praskovya. (1904). "Svanetia” (Svaneti). Kavkaz. Puteviya Zametki (Caucasus. Travel Notes): pp. 255-317. Moscow: Tipografiya obshestva rasprpostraneniya poleznikh knig. 